06

\title{
Влияние добавления диборана на свойства плазмохимически осаждаемых углеродных пленок
}

\author{
(C) Е.Н. Шубина ${ }^{1}$, П.А. Карасёв ${ }^{1}$, А.И. Титов ${ }^{1}$, О.А. Подсвиров ${ }^{1}$, \\ А.Я. Виноградов ${ }^{2}$, Н.Н. Карасёв ${ }^{3}$, А.В. Поздняков ${ }^{1}$ \\ ${ }^{1}$ Санкт-Петербургский политехнический университет Петра Великого \\ ${ }^{2}$ Физико-технический институт им. А.Ф. Иоффе РАН, Санкт-Петербург \\ ${ }^{3}$ Санкт-Петербургский национальный исследовательский университет \\ информационных технологий, механики и оптики \\ E-mail: katerinashubina@gmail.com
}

Поступило в Редакцию 20 октября 2015 г. В окончательной редакции 18 июля 2016 г.

Представлены результаты исследований оптических, электрических, механических свойств алмазоподобных углеродных пленок, полученных методом плазмохимического газофазного осаждения из смеси диборана и метана в различных пропорциях. При достижении пороговой концентрации $(\sim 12 \%)$ диборана в рабочей смеси, в структуре пленок начинают формироваться включения новой фазы. Это приводит к нелинейной зависимости внутренних напряжений и поверхностного сопротивления получаемых покрытий от состава смеси с минимальными значениями при концентрации диборана $\sim 12 \%$.

DOI: 10.21883/PJTF.2017.01.44093.16031

Изучению алмазоподобных пленок (Diamond Like Carbon, DLC) уделяют пристальное внимание благодаря уникальному сочетанию оптических, механических, электрических и химико-биологических свойств данного материала [1,2]. Тонкие DLC-пленки, с одной стороны, уже применяются в промышленности в качестве различного рода оптических и защитных покрытий [3], а с другой - продолжают оставаться объектом активного исследования. Так в работе [4] продемонстрировано увеличение эффективности кремниевых солнечных элементов после напыления просветляющей DLC-пленки. Показаны перспективы их использования и для высокочувствительных тонкопленочных резистивных термометров, работающих вблизи комнатной температуры [5], для 
создания оптически прозрачных инертных электродов в приложениях электрохимии $[6,7]$, для создания датчиков давления на основе диодов Шоттки металл-DLC-полупроводник [8], в качестве антифрикционных и биологически инертных покрытий на имплантаты [9] и др. Учитывая весь комплекс свойств, можно уверенно предсказать успешное использование таких пленок и в будущем: в микро- и наноэлектронике, электрохимии, медицине и в биосенсорике. Зачастую требуются электропроводящие DLC-покрытия, а как известно, аморфный углерод существует в природе в виде полупроводника со сложной структурой, высокой плотностью собственных дефектов и очень малой проводимостью [10]. Естественным путем решения указанной проблемы может быть модификация материала путем введения примесей. Легирование можно осуществить во время процесса выращивания DLC-пленки. В зависимости от условий роста и способа легирования можно получить алмазоподобные пленки с различной структурой и свойствами. В качестве примесей чаще всего рассматривают азот, бор, фтор, фосфор, различные металлы [2]. В этом ряду особенно интересны атомы бора, поскольку бор - один из немногих лигандов, которые могут замещать углеродные атомы в алмазной решетке как геометрически (ковалентный радиус атома бора равен $0.088 \mathrm{~nm}$, а атома углерода $-0.077 \mathrm{~nm})$, так и энергетически [11].

Для выращивания DLC-покрытий удобно использовать метод высокочастотного плазмохимического газофазного осаждения (RF PECVD), поскольку он дает возможность нанесения углеродных пленок с широким набором разнообразных свойств при равномерном распределении внедренной примеси. В настоящей работе представлены результаты экспериментальных исследований влияния добавления диборана $\left(\mathrm{B}_{2} \mathrm{H}_{6}\right)$ в различных концентрациях к метану в реакционной смеси в процессе выращивания DLC-пленок методом RF PECVD на их механические, оптические и электрические свойства.

Использовалась система с плоскими электродами, подложки располагались на заземленном электроде. Давление рабочей смеси $\mathrm{CH}_{4}+\mathrm{B}_{2} \mathrm{H}_{6}$ во время процесса осаждения равнялось 30 mTorr, температура подложки $300^{\circ} \mathrm{C}$. Мощность возбуждения плазмы $100 \mathrm{~W}$, напряжение смещения $200 \mathrm{~V}$. Данный режим был выбран как наиболее оптимальный с точки зрения качества готовых покрытий (однородность, механическая прочность и т.д.) [12,13]. Пленки выращивались на кремниевых пластинах $(100)$ КДБ-10 размером $10 \times 30 \mathrm{~mm}$. Для достижения

6 Письма в ЖТФ, 2017, том 43, вып. 1 
наилучшей адгезии пленки к подложке использовалась трехступенчатая процедура предварительной обработки подложки, подробно описанная в [12]. Толщина покрытия составляла $100-200 \mathrm{~nm}$, контролировалась лазерным интерферометром в процессе выращивания и дополнительно измерялась микроинтерферометром МИИ-4 на границе пленки после окончания процесса осаждения.

Спектры комбинационного рассеяния снимались на приборе Renishaw InVia Raman microscope c возбуждением на длине волны $514 \mathrm{~nm}$ мощностью $20 \mathrm{~mW}$. ИК-спектры поглощения измерялись на фурье-спектрометре Bruker Vertex 80v. Величины остаточных напряжений рассчитывались по формуле Стони [14] на основе интерферометрических измерений радиуса кривизны подложки до и после осаждения пленки. Сопротивление покрытий определялось четырехзондовым методом на пленках, полученных на оксидированном кремнии. Для всех образцов выполнялась серия измерений на нескольких различных участках.

Добавление диборана к рабочему газу во всех случаях приводит к снижению скорости роста пленок (в несколько раз), тем сильнее, чем выше концентрация примеси.

На рис. 1 представлен ряд спектров поглощения полученных борсодержащих алмазоподобных пленок в диапазоне от 750 до $1800 \mathrm{~cm}^{-1}$ за вычетом спектра поглощения DLC-пленки, выращенной в идентичных условиях, но без $\mathrm{B}_{2} \mathrm{H}_{6}$. На вставке рисунка для справки представлены исходные спектры пропускания исследуемых образцов.

Каждый полученный спектр раскладывался на четыре гауссовых пика поглощения $A, B, C$ и $D$, максимумы которых возникают при минимальной концентрации $\mathrm{B}_{2} \mathrm{H}_{6}$ на $800,1050,1280$ и $1540 \mathrm{~cm}^{-1}$. Зависимости высот соответствующих пиков от концентрации диборана в рабочем газе представлены на рис. 2, $a$. Отметим, что непосредственно на спектрах пик $B$ перекрывается с более интенсивным пиком на $1104 \mathrm{~cm}^{-1}$, характеризующим антисимметричные колебания $\mathrm{SiO}_{2}$-связей [15]. Однако последний имеет существенно меньшую ширину, что позволяет их разделять.

Как видно из рисунка, пик поглощения $A$ появляется при концентрации диборана $\sim 12 \%$ и далее линейно растет с ее увеличением. Пик $B$ также практически отсутствует до концентрации $\mathrm{B}_{2} \mathrm{H}_{6} \sim 12 \%$, после чего начинается резкий рост его высоты с увеличением содержания примеси. Из литературы известно, что пик $A$ соответствует колебаниям

Письма в ЖТФ, 2017, том 43, вып. 1 


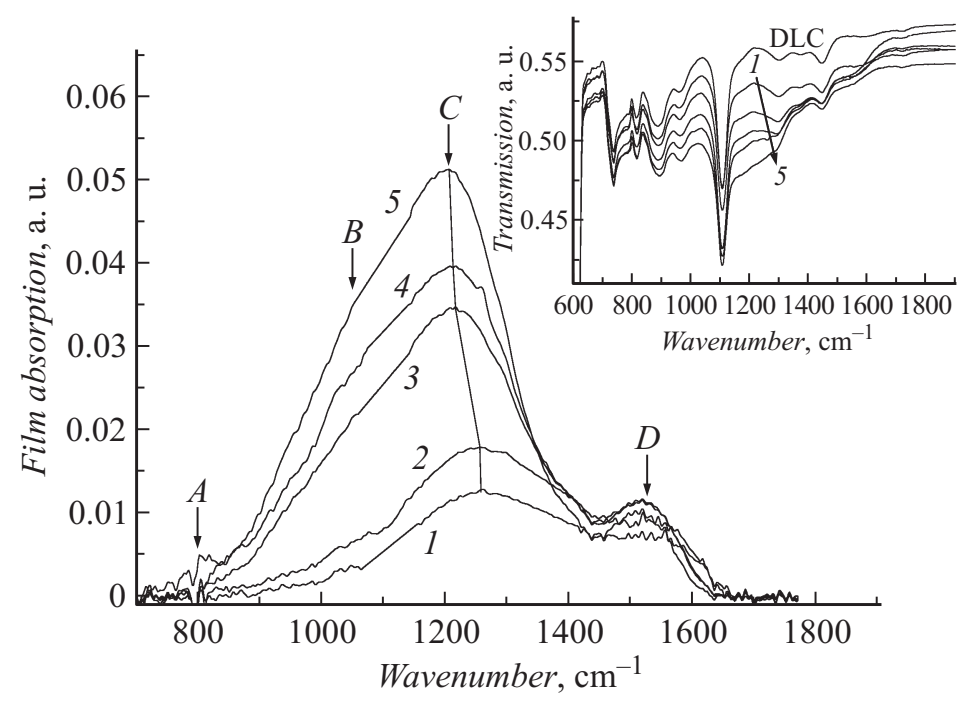

Рис. 1. ИК-спектры поглощения борсодержащих углеродных пленок, полученных при различном содержании диборана в рабочей смеси за вычетом спектра алмазоподобной пленки, выращенной из чистого метана. На вставке представлены исходные ИК-спектры пропускания тех же пленок. Цифры последовательно отвечают концентрациям 4, 10, 15, 20 и $25 \%$ диборана в смеси соответственно.

В-В-связей в аморфной сетке [16], пик $B$ вызван колебаниями локализованных валентных В-С-связей в тетраэдрическом карбиде бора $[16,17]$. Таким образом, причина появления обоих этих пиков одна - при высоких концентрациях диборана в пленке начинает формироваться новая фаза углерод-борных соединений, вероятно, наночастицы карбида бора.

Величина максимума пика $C$ линейно растет во всем диапазоне концентраций диборана в рабочей смеси. Согласно [18-20], этот пик вызван колебаниями В-С-связей в цепочках и его поведение, повидимому, отражает линейное увеличение содержания бора в пленке. Зависимость для пика $D$ также имеет линейный характер в области малых концентраций $\mathrm{B}_{2} \mathrm{H}_{6}$, и затем выходит на насыщение после величины $15 \%$. Эта полоса поглощения характеризует собственные $\mathrm{B}-\mathrm{C}$-колебания в цепях $\mathrm{C}-\mathrm{B}-\mathrm{B}$ или $\mathrm{C}-\mathrm{B}-\mathrm{C}[21]$. При этом, как

6* Письма в ЖТФ, 2017, том 43, вып. 1 


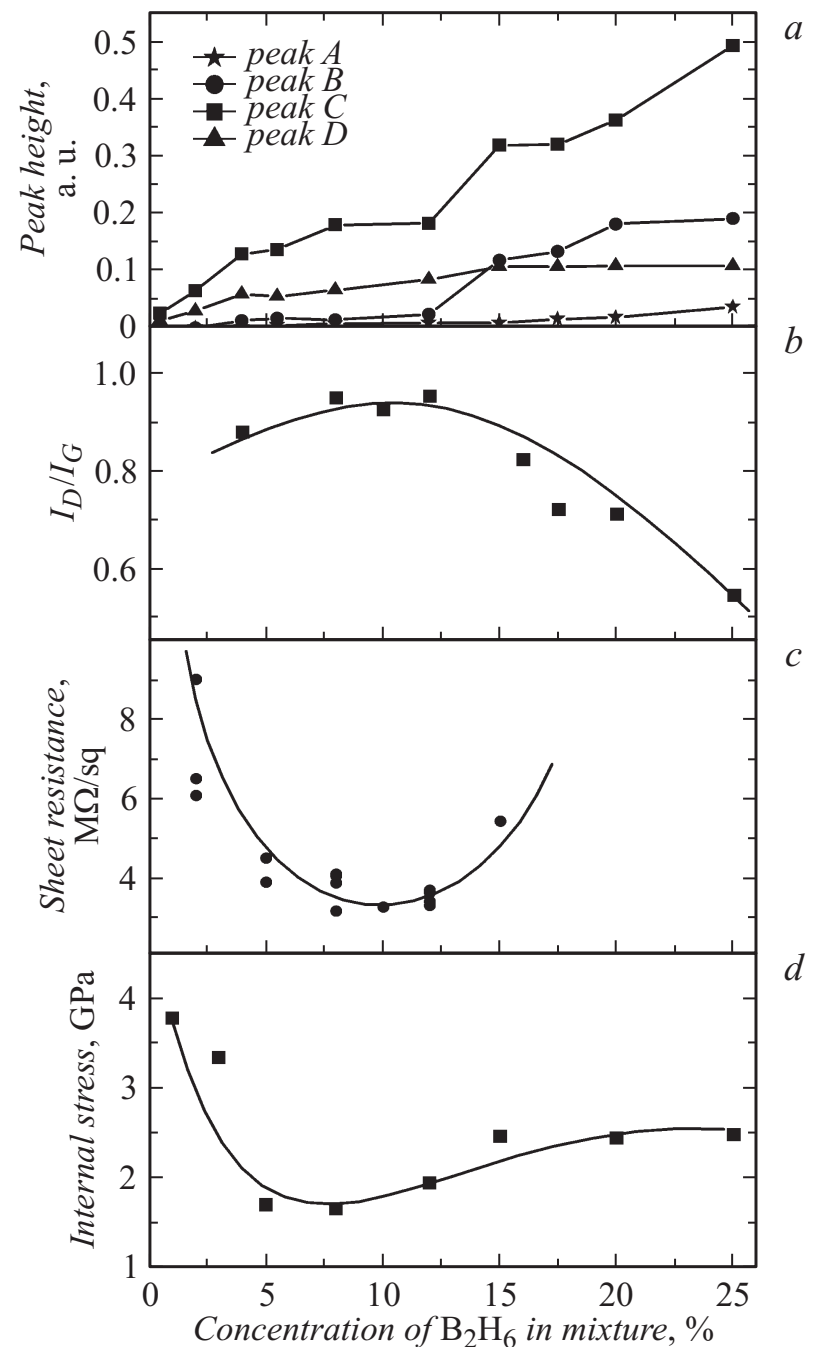

Рис. 2. Зависимости от концентрации диборана в рабочей смеси: $a-$ высот пиков ИК-поглощения, $b$ - отношения интенсивностей пиков $D$ и $G$ в спектрах комбинационного рассеяния, $c$ - поверхностного сопротивления, $d-$ остаточных механических напряжений борсодержащих алмазоподобных пленок.

Письма в ЖТФ, 2017, том 43, вып. 1 


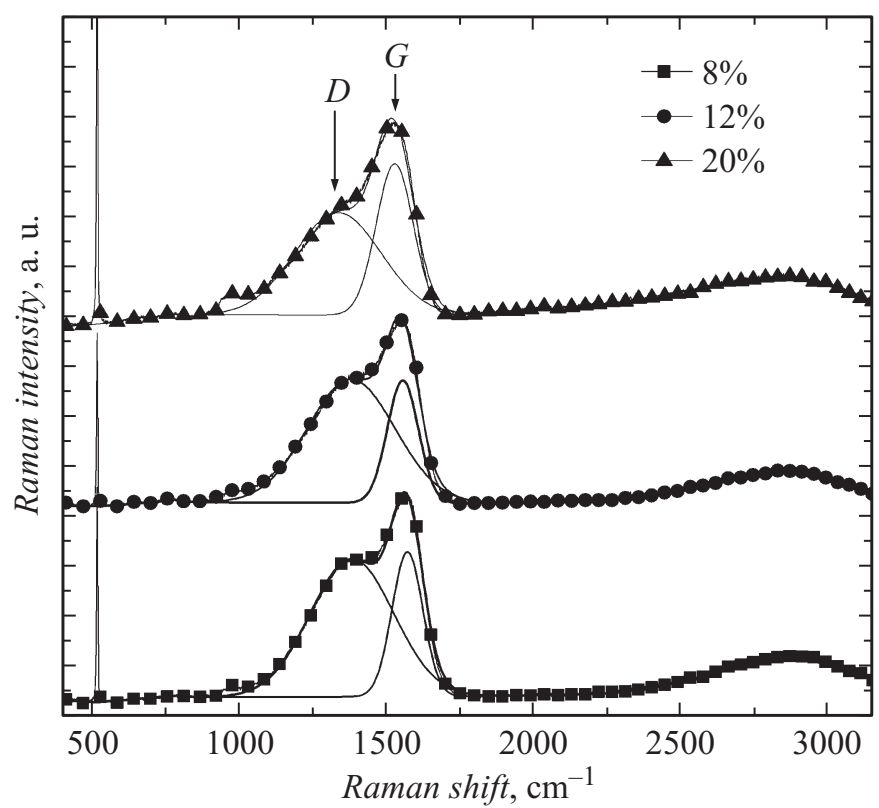

Рис. 3. Спектры комбинационного рассеяния от пленок, выращенных при различных концентрациях диборана в рабочей смеси. Обозначены характерные $D$ и $G$-пики и приведены соответствующие разложения. Спектры раздвинуты по вертикальной оси для ясности рисунка. Символом показана только одна из 50 экспериментальных точек.

видно из рис. 1 , с ростом содержания $\mathrm{B}_{2} \mathrm{H}_{6}$ в смеси происходит смещение максимумов обоих пиков $C$ и $D$ в сторону меньших длин волн, которое объясняется увеличением концентрации атомов бора, замещающих атомы углерода в пленке [19-22].

Таким образом, анализ полученных ИК-спектров показал, что на положение и интенсивность характерных пиков поглощения влияет как усиливающееся с ростом концентрации диборана замещение углеродных атомов атомами бора в пленке, так и появление новых связей В-B или новой фазы.

На рис. 3 приведены спектры комбинационного рассеяния в видимом диапазоне длин волн для пленок, полученных при трех раз-

Письма в ЖТФ, 2017, том 43, вып. 1 
личных концентрациях диборана. Пики в районе 500 и $960 \mathrm{~cm}^{-1}$ соответствуют рассеянию в кремниевой подложке. Также на рис. 3 четко виден характерный для аморфных углеродных пленок сложный максимум, состоящий их двух, называемых $D$ (в районе $1330 \mathrm{~cm}^{-1}$ ) и $G$ (в районе $\left.1550 \mathrm{~cm}^{-1}\right)$ пиков, которые отвечают возбуждению $s p^{2}$-гибридизированных связей в пленках [23]. Для анализа поведения свойств пиков при изменении состава рабочей смеси мы использовали разложение на две гауссовы функции [23]. Зависимость отношения интенсивностей полученных пиков $\left(I_{D} / I_{G}\right)$ от концентрации диборана представлена на рис. 2, $b$. Как видно из графика, $I_{D} / I_{G}$ остается практически постоянным до пороговой концентрации диборана в смеси ( 12\%), после чего происходит линейное его уменьшение. Поскольку одновременно происходит сдвиг положения $G$-пика в область меньших значений волновых векторов, такой характер зависимости косвенно свидетельствует об увеличении концентрации $s p^{3}$-гибридизованных связей атомов углерода $[1,24]$.

Поверхностное сопротивление „чистой“ DLC и пленок, полученных при малых концентрациях диборана (менее 3\%), имеет величину порядка нескольких сотен $\mathrm{M} \Omega / \square$, корректно измерить которую на имеющейся у нас аппаратуре затруднительно. На рис. 2, с представлены зависимости поверхностного сопротивления образцов при более высоких концентрациях диборана в рабочей смеси. Из рисунка видно, что добавка $\mathrm{B}_{2} \mathrm{H}_{6}$ приводит к существенному уменьшению сопротивления. Оно достигает минимума в области $10 \%$ содержания диборана в смеси, а затем начинает расти. Сопротивление пленок, полученных при концентрациях более $15 \%$, опять существенно возрастает.

Похожую зависимость от концентрации $\mathrm{B}_{2} \mathrm{H}_{6}$ можно наблюдать и для величины внутренних механических напряжений в пленках (рис. 2,d). Здесь также присутствует характерный минимум в области 10-12\% $\mathrm{B}_{2} \mathrm{H}_{6}$ после чего величина напряжений несколько увеличивается и выходит на насыщение.

Таким образом, исследовано влияние добавления диборана к метану в реакционной смеси в процессе выращивания на свойства алмазоподобных пленок. Обнаружено, что с ростом содержания диборана в смеси происходит практически линейное увеличение концентрации бора и содержания $s p^{3}$-гибридизованных углеродных связей в пленке. При небольшой добавке $\mathrm{B}_{2} \mathrm{H}_{6}$, атомы бора встраиваются в структуру покрытия, замещая атомы углерода. При достижении пороговой кон-

Письма в ЖТФ, 2017, том 43, вып. 1 
центрации ( 12\%) диборана в рабочей смеси, в структуре пленок начинают формироваться включения новой фазы, по-видимому, - карбида бора. Такое изменение структуры пленок приводит к наблюдающимся нелинейным зависимостям внутренних напряжений и поверхностного сопротивления от концентрации газовой смеси, с пологим минимумом в области $10-12 \% \mathrm{~B}_{2} \mathrm{H}_{6}$.

Авторы благодарят доц. А.Н. Софронова из СПбПУ за проведение ИК-измерений.

\section{Список литературы}

[1] Robertson J. // Mater. Sci. Eng. R. 2002. V. 37. P. 129.

[2] Erdemir A., Donnet C. (Eds.) Tribology of Diamond-Like Carbon Films. Springer Science - Business Media. LLC, 2008.

[3] Casiraghi C., Robertson J., Ferrari A.C. // Mater. Today 2007. V. 10 (1-2). P. 44.

[4] Ismail R.A., Mousa A.M., Hassan M.A. et al. // Opt. Quant. Electron. 2016. V. 48. P. 16.

[5] Sikora A., Berkesse A., Bourgeois O. et al. // Appl. Phys. A. 2009. V. 94. P. 105.

[6] Zeng A., Neto V.F., Gracio J.J. et al. // Diam. Rel. Mat. 2014. V. 43. P. 12.

[7] Kavana L., Zivcovaa Z.V., Petrak V. et al. // Electroch. Acta. 2015. V. 179. P. 626.

[8] Basman N., Aslan N., Uzun O. et al. // Microelectr. Eng. 2015. V. 140. P. 18.

[9] Hauert R., Thorwarth K., Thorwarth G. // Surf. Coat. Technol. 2013. V. 233. P. 119.

[10] Veerasamy V.S., Amaratunga G.A.J., Davis A.A. et al. // J. Phys.: Condens. Matter. 1993. V. 5. P. 169.

[11] Goss J.P., Eyre R.J., Briddon P.R. // Physics and Applications of CVD Diamond. Koizumi S., Nebel C., Nesladek M., Eds. Weinheim, German: John Wiley \& Sons, 2008. P. 199.

[12] Подсвиров О.А., Карасев П.А., Виноградов А.Я. и др. // Поверхность. 2010. № 3. C. 81.

[13] Karaseov P.A., Podsvirov O.A., Karabeshkin K.V. et al. // Nucl. Instr. Meth. Phys. Res. B. 2010. V. 268. P. 3107.

[14] Stoney G.G. // Proc. Roy. Soc. A. 1909. V. 82. P. 172.

[15] Boyd I.W. // Appl. Phys. Lett. 1987. V. 51. P. 418.

[16] Shirai K., Emura S., Gonda S. et al. // J. Appl. Phys. 1995. V. 78. P. 3392.

[17] Blum N.A., Feldman C., Satkiewicz F.G. // Phys. Stat. Sol. (a). 1997. V. 41. P. 481.

Письма в ЖТФ, 2017, том 43, вып. 1 
[18] Stein H., Aselage T., Emin D. // Proc. 10th Int. Symp. on Boron, Borides and Related Compounds. Ed. by H. Werheit. 1987. P. 322.

[19] Lin Shu-Han, Feldman B.J. // Solid State Commun. 1998. V. 107. N 5. P. 239.

[20] Stein H., Aselage T., Emin D. // Proc. 10th Int. Conf. on Boron, Borides and Related Compounds. AIP Conf. Proc. New York, 1991. V. 231. P. 322.

[21] Kuhlmann U., Werheit H., Schwetz K.A. // J. Alloys Compd. 1992. V. 189. P. 249.

[22] Annen A., Sab M., Beckmann R. et al. // Thin Solid Films. 1998. V. 312. P. 147.

[23] Ferrari A.C., Robertson J. // Phys Rev. B. 2000. V. 61. N 20. P. 14095.

[24] Tamor M.A., Vassel W.C. // J. Appl. Phys. 1994. V. 76. P. 3823. 